\title{
Burden and characteristics of HIV infection among female sex workers in Kampala, Uganda - a respondent-driven sampling survey
}

Wolfgang Hladik ${ }^{1 *}$, Andrew L. Baughman ${ }^{1}$, David Serwadda², Jordan W. Tappero ${ }^{3}$, Rachel Kwezi', Namakula D. Nakato ${ }^{4}$ and Joseph Barker ${ }^{1}$

\begin{abstract}
Background: Sex workers in Uganda are at significant risk for HIV infection. We characterized the HIV epidemic among Kampala female sex workers (FSW).

Methods: We used respondent-driven sampling to sample FSW aged 15+ years who reported having sold sex to men in the preceding 30 days; collected data through audio-computer assisted self-interviews, and tested blood, vaginal and rectal swabs for HIV, syphilis, neisseria gonorrhea, chlamydia trachomatis, and trichomonas vaginalis.

Results: A total of 942 FSW were enrolled from June 2008 through April 2009. The overall estimated HIV prevalence was $33 \%$ (95\% confidence intervals [CI] 30\%-37\%) and among FSW 25 years or older was 44\%. HIV infection is associated with low levels of schooling, having no other work, never having tested for HIV, self-reported genital ulcers or sores, and testing positive for neisseria gonorrhea or any sexually transmitted infections (STI). Two thirds (65\%) of commercial sex acts reportedly were protected by condoms; one in five (19\%) FSW reported having had anal sex. Gender-based violence was frequent; 34\% reported having been raped and 24\% reported having been beaten by clients in the preceding 30 days.
\end{abstract}

Conclusions: One in three FSW in Kampala is HIV-infected, suggesting a severe HIV epidemic in this population. Intensified interventions are warranted to increase condom use, HIV testing, STI screening, as well as antiretroviral treatment and pre-exposure prophylaxis along with measures to overcome gender-based violence.

Keywords: Female sex workers, HIV, STI, Kampala, Uganda, RDS, Respondent-driven sampling

\section{Background}

By the end of 2014, there were near 37 million people living with HIV globally, with more than 5000 new infections per day the majority of which occur in sub-Saharan Africa [1]. UNAIDS has put forward a bold vision to end the global HIV epidemic by 2030, [2] beginning by first meeting the 90-90-90 "fast-track" targets by $2020{ }^{1}$ These achievements are only possible by implementing comprehensive packages of prevention and HIV care services for all populations, especially those with highest HIV burden, incidence, and transmission rates.

\footnotetext{
* Correspondence: wfh3@cdc.gov

${ }^{1}$ Division of Global HIV and TB, Center for Global Health, Centers for Disease

Control and Prevention, 1600 Clifton Rd, Atlanta, GA 30333, USA

Full list of author information is available at the end of the article
}

Key populations, including sex workers, are critical to controlling the HIV pandemic. A recent review estimated that female sex workers (FSW) are 13.5 times more likely to be HIV infected than other women [3]. Sex workers require tailored public health interventions that address critical gaps in HIV prevention, HIV testing, case-finding, linkage, retention, and adherence to antiretroviral therapy. Although encouraging progress has been made in stabilizing HIV prevalence and promoting condom use among sex workers in some locations, substantially greater gains will be needed to reduce the rate of sexual HIV transmission among sex workers and their partners by 2020 [4]. FSW are at increased risk for HIV due to frequent sex with numerous clients, inconsistent 
condom use, anal sex, and drug use, as well as violence, stigma and discrimination, and impeded access to HIV services [5-7]. An estimated 15\% of HIV infections worldwide may be due to sex work, with sub-Saharan Africa having the highest attributable fraction (17.8\%) [8].

Uganda faces a generalized epidemic with an estimated adult HIV prevalence of 7.3\% [9] and an HIV incidence that remains stubbornly stable [4]. In Kampala, Uganda's capital, a cohort of high-risk women, most of whom reported engaging in selling sex, had a baseline HIV prevalence of $37 \%$ [10]. Sex work in Uganda is illegal and likely contributes disproportionally to the overall burden of disease; indeed, a Modes of Transmission study estimated that sex work-related HIV transmissions may account for $10 \%$ of incident HV infections [11].

As a socially hidden population, sex workers are often highly mobile, transitioning in and out of sex work as dictated by economic needs. Surveys using proper sampling designs for such populations are difficult and challenging, and thus convenience sampling designs are commonly used. We report here on the first biobehavioral survey undertaken among FSW in Kampala that used a rigorous sampling design and thus generated population estimates for this important high-risk group. Our data collection and analysis was based on a conceptual framework in which social factors influence sexual and drug use behaviors that in turn affect HIV infection risk. The survey's objectives were to: (1) estimate the burden of HIV and other sexually transmitted infections (STI), (2) estimate the burden of self-reported key behavioral measures relevant for HIV and STI control in this population, and (3) investigate risk factors associated with HIV infection.

\section{Methods \\ Survey design}

We conducted a cross-sectional biobehavioral survey among FSW in Kampala, Uganda, using respondentdriven sampling (RDS). Pre-survey formative research with eight key informants, including government officials, sex workers, and previous survey investigators using a qualitative interview guide suggested that RDS should be favored over venue-based sampling and informed seed identification, social connectedness, compensation for survey participation, as well as other survey procedures.

\section{Study population}

Survey eligibility criteria included female sex, age $\geq 15$ years, residence in greater Kampala, and self-reported selling of sex to one or more men during the 30 days preceding survey enrollment. Candidate recruits who received their coupons from strangers were excluded, as one of the functional RDS assumptions includes that recruiter and recruit know one another.

\section{Sampling}

RDS methodology is well described elsewhere [12-14] and is commonly used to sample socially hidden populations. Sampling began with nine seeds and recruits received three coupons each as well as a brief training for peer referral. Recruits would give a coupon to a peer; only by presenting a coupon one could enroll in the survey. Due to a high coupon redemption rate, the number of coupons was quickly reduced to two coupons per recruits for most of the sampling period and further reduced to one towards the end of the survey. Recruits presented their coupons at the single survey office in downtown Kampala. Survey data were collected between June 2008 and April 2009.

In total, 2120 coupons were issued and 1100 (52\%) were redeemed; an additional 40 coupons were deemed invalid. Of the 1100 candidate recruits, 949 (86\%) were considered eligible, consented, and enrolled. Of these, 942 (99\%) were interviewed and received HIV testing. The number of waves per seed varied between 1 and 25; equilibrium (i.e., the point in sampling when the distribution of a given characteristic stabilizes) for both HIV infection and age was reached after wave 2. Figure 1 displays the sampling tree; Table 1 shows the recruitment matrix by HIV status and age group.

\section{Survey office procedures}

After recruits' coupons were verified, CD and MP3 players were used to inform recruits about specific interview terms used (such as the different types of sex, frequency of sex, partner types), peer recruitment, and other relevant survey information. Candidate participants were then screened for eligibility and consented face-to-face. Thereafter, a short computer-based tutorial about audiocomputer-assisted self-interviewing (ACASI) preceded the actual ACASI; a small fraction who could not complete the ACASI were interviewed face-to-face. Following the interview, recruits underwent pre-test counseling for HIV and STI testing and had venous blood as well as vaginal and rectal swab specimens collected. At the end of the first visit, recruits received instructions and coupons for peer recruitment. Recruits were asked to return to the survey office two weeks later to receive post-test counseling for HIV and other test results, treatment for non-HIV associated STI, or referral letters for HIV care/treatment providers in case of HIV-positive results.

\section{Data measures}

In addition to basic demographic data, our main data variables of interest included lifetime sexual characteristics, 


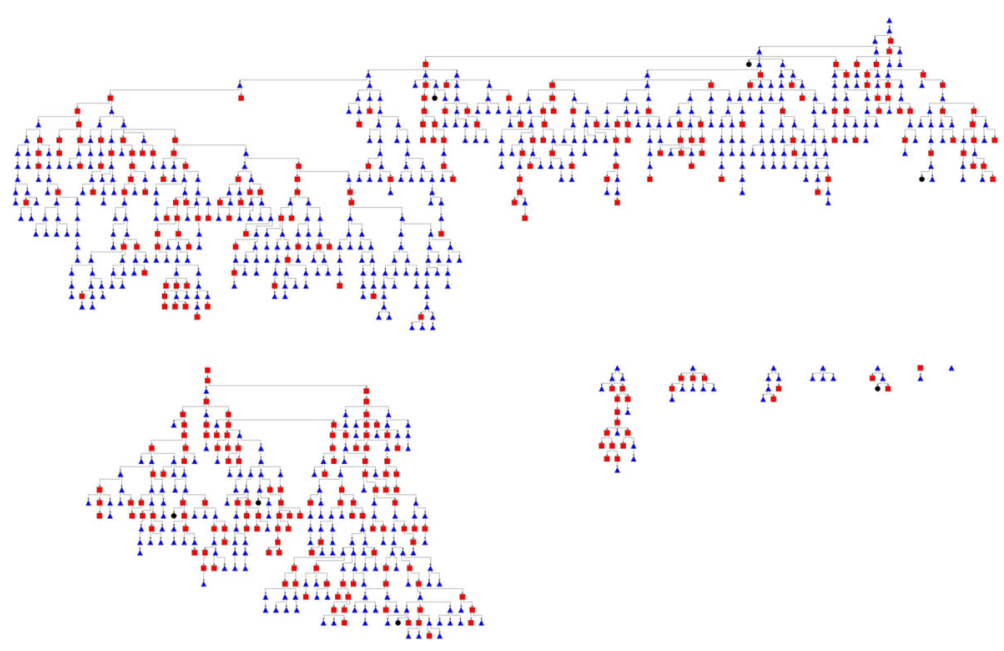

Fig. 1 Diagram of the recruitment chains produced by yEd software (version 3.10.2). For the 949 nodes (FSW), 323 had a positive HIV test result (red square), 619 had a negative result (blue triangle), and 7 had a missing value (black circle)

sexual experiences in the last 30 days, sexual violence, self-reported alcohol and drug use, sexually transmitted disease (STD) symptoms, access to HIV services, and HIV-related perceptions. We probed blackmail through the question "Have you ever been blackmailed by someone because you sell sex?", and knowledge on transmission risk by mode of intercourse through the question "What kind of sex do you think is more dangerous to get HIV?" We probed alcohol consumption as having ever drunk alcohol, probed the frequency of alcohol drinking in the last 30 days and prior to the last sex act, and defined a drink of alcohol as "one bottle of beer, one glass of wine, or one shot of whisky or waragi."

\section{Laboratory measures}

Specimens were transported daily to the laboratory. Laboratory testing was performed at the STD Reference Laboratory based at Mulago Hospital, Kampala. Testing for HIV-1 antibodies was performed in parallel using Vironostika $^{\circ}$ HIV Uniform II plus O2 (bioMeriéux, Marcy l'Etoile, France) and Murex HIV Ag/Ab Combination (Abbott Laboratories, Abbott Park, Illinois, U.S.A.). Serological testing for Treponema pallidum (TP) was performed with anti-syphilis IgG ELISA (Biotec

Table 1 Recruiter-recruit matrix by HIV status and age group

\begin{tabular}{llll}
\hline & & \multicolumn{2}{l}{ Recruit } \\
\cline { 3 - 4 } & HIV status & Negative & Positive \\
\hline Recruiter & Negative & $407(70 \%)$ & $174(30 \%)$ \\
& Positive & $205(58 \%)$ & $147(42 \%)$ \\
& Age & $15-24$ years & $25+$ years \\
& $15-24$ years & $178(51 \%)$ & $172(49 \%)$ \\
& $25+$ years & $220(38 \%)$ & $363(62 \%)$ \\
\hline
\end{tabular}

Laboratories, Suffolk, UK) and, if reactive, the Rapid Plasma Reagin Syfacard-R Test (Murex Biotech, Dartford, UK) to detect current TP infection. Vaginal and rectal swabs were tested for Neisseria gonorrhea (NG) and Chlamydia trachomatis (CT) DNA using Cobas Amplicor or Amplicor PCR (Roche Diagnostics, Branchburg, New Jersey, U.S.A.). Using microscopy, we evaluated vaginal swabs for the presence of bacterial vaginosis, and Trichomonas vaginalis utilizing InPouch (BioMed Diagnostics, Inc., White City, Oregon, USA).

\section{Data management and analysis}

For sample size calculations, we assumed an HIV prevalence of $25.2 \%$, approximately twice that of urban Ugandan women in general [15] (no probability-based previous survey estimates for FSW in Kampala were available), and a design effect of 2 [16], and determined that a minimum target sample size of approximately 600 would yield acceptable 95\% confidence intervals (CI). Interview data were cleaned using Statistical Analysis Software - SAS v9.3 (SAS Institute, Cary, North Carolina). To account for social network size and recruitment patterns, we calculated individualized weights using RDSAT version 7.1.38 software (www.respondentdrivensampling.org). For categorical variables the RDS-based weights were applied to the data and each FSW was treated as a primary sampling unit using SAS-callable SUDAAN software [17]. For several continuous variables, we calculated the median (interquartile range, IQR) using unweighted data.

Chi-squared tests of independence between each characteristic and the HIV outcome were performed. In addition, we calculated prevalence ratios and 95\% CI [18]. Because numerous characteristics of FSW were associated with HIV infection, we used a hierarchical conceptual 
framework for building a multivariable model for HIV infection [19]. First, we included sociodemographic factors associated with HIV infection at a level of $P<0.2$ in bivariate analysis in a backward elimination model selection procedure and retained factors in the model that were independently associated with HIV infection $(P<0.05)$. Next, we considered this core set of sociodemographic factors plus behavioral factors that were associated with HIV infection at a level of $P<0.2$ in bivariate analysis in a second backward elimination model selection procedure. The final set of sociodemographic and behavioral factors independently associated with HIV infection were included in a separate multivariable model for each of the other sexually transmitted infections.

\section{Human subjects considerations}

The survey was conducted anonymously; we obtained verbal informed consent but collected no personal identifiers. Recruits had their fingerprints scanned (images were not stored) to generate unique alphanumeric codes and facilitate linking visits, detecting duplicate enrollment attempts or coupons that were issued to other recruits. Several different surveys were carried out at the same time using the same survey office, thus masking the group identity of respondents visiting the survey office. We compensated recruits for their time and transport costs (US \$3.00), and, at the return visit, recruitment efforts (US $\$ 1.00$ per successfully recruited eligible peer). For FSW under the age of 18 who indicated that they were forced into sex work, procedures were in place to refer such persons to relevant service providers.

\section{Results}

\section{Population characteristics}

Table 2 displays select characteristics of FSW in Kampala. Almost all (95\%) were of Ugandan nationality and $44 \%$ were $15-24$ years old (median age: 26 years). Most (83\%) FSW have ever been to school, and 51\% had completed at least 7 years of schooling, equivalent to primary school education. Most (66\%) FSW had ever been married and most had had at least one pregnancy in their lifetime (91\%). The median number of pregnancies was 3 (IQR: $1-4$ ), and 25\% had ever had an abortion. Family planning use was relatively common, with $67 \%$ using a modern method, including injectables (34\%) and oral contraceptives (31\%).

\section{Sex work characteristics}

The median duration of sex work at time of survey participation was 3 years (IQR: 2-6); the median age of first selling sex was 22 years (IQR 18-26). For most (57\%), sex work was the only available income. The median fee for sex was approximately US \$3 (IQR \$2-5). FSW meet their clients mostly (71\%) on the street, and have sex with them mostly at their or someone else's home (88\%). Almost half (46\%) of FSW have ever been forced to have sex, and $34 \%$ reported being raped in the last 30 days. Out of the times being raped (defined as being forced or threatened to be hurt to have vaginal or anal sex) in the last 30 days, $26 \%$ were by a customer, and $16 \%$ by security personnel or police. Some of these incidents were reported to the police $(17 \%)$ and health care was sought $(18 \%)$. Beatings by clients in the last 30 days were reported by $24 \%$ of FSW. Blackmail due to knowledge by someone of their sex work was low (16\%). A small proportion (3\%) ever sold sex to women. In the preceding 12 months, $14 \%$ of FSW had sold sex outside of Kampala.

\section{HIV-related risk behaviors and perceptions}

During the last sex act with a male client, two thirds (65\%) used a condom and $14 \%$ used a lubricant; $11 \%$ reported that they were forced to have sex. Additionally, 9\% reported to have taken illicit drugs prior to that sex act and half (49\%) said they had drunk alcohol.

Lifetime alcohol use was reported by $77 \%$, with $29 \%$ had been drinking every day over the last 30 days with an average number of 2.9 drinks the last time they had consumed alcohol. Drug use, including sniffing glue or petrol, or consuming marijuana, khat (a plant-based mild stimulant), cocaine, or other drugs was reported by $24 \%$. A lifetime history of injecting drug use was reported by $4 \%$. Half (49\%) of FSW had sex with 8 or more men (including intimate partners) over the preceding 30 days. The median proportion of condom use for all male partners in the last 30 days was 60\% (IQR 24$88 \%$ ), with $18 \%$ of FSW having used condoms $100 \%$ of the time. Approximately one fifth (19\%) of sex workers ever had anal sex and 15\% had anal sex in the last 30 days; among these, the median number of anal sex acts in the last 30 days was 3 . Among FSW who ever had anal sex, $30 \%$ felt it was less important to use condoms for anal sex compared to vaginal sex. Only 15\% thought anal sex put them at higher risk of contracting HIV than vaginal sex.

\section{HIV services uptake}

The majority (53\%) of FSW had previously tested for HIV, and $16 \%$ had tested in the preceding 12 months. Among those who ever tested for HIV, 92\% reportedly tested negative and $8 \%$ told their HIV (negative or positive) status to their sex partners; $89 \%$ did not reveal their HIV status to anyone. Of those who reported having tested negative, $16 \%$ were found to be HIV-positive. Among those who were known HIV- 
Table 2 Characteristics of female sex workers in Kampala, Uganda, 2008-09, N=942

\begin{tabular}{|c|c|c|c|}
\hline Characteristic $^{a}$ & $n$ & Sample \% & $\begin{array}{l}\text { Weighted \% } \\
(95 \% \text { Cl) }\end{array}$ \\
\hline \multicolumn{4}{|l|}{ Age, years } \\
\hline $15-19$ & 109 & 11.6 & $12.6(9.9-15.6)$ \\
\hline $20-24$ & 292 & 31.0 & $32.4(28.4-36.1)$ \\
\hline $25-29$ & 248 & 26.3 & $25.5(22.3-28.8)$ \\
\hline $30+$ & 293 & 31.1 & $29.6(25.8-33.6)$ \\
\hline \multicolumn{4}{|l|}{ Nationality } \\
\hline Ugandan & 897 & 95.7 & $95.4(93.7-96.9)$ \\
\hline Not Ugandan & 40 & 4.3 & $4.6(3.0-6.3)$ \\
\hline \multicolumn{4}{|l|}{ Schooling, years } \\
\hline None & 149 & 16.2 & $17.3(14.3-20.3)$ \\
\hline $1-3$ & 103 & 11.2 & $12.0(9.1-14.7)$ \\
\hline $4-6$ & 185 & 20.1 & $19.7(16.8-23.0)$ \\
\hline $7+$ & 482 & 52.6 & $51.0(46.9-55.4)$ \\
\hline \multicolumn{4}{|l|}{ Marital status } \\
\hline Never married & 301 & 32.2 & $33.8(29.9-37.9)$ \\
\hline Cohabitating & 210 & 22.5 & $22.3(19.3-25.6)$ \\
\hline Married (mono) & 55 & 5.9 & $5.9(4.2-7.5)$ \\
\hline Married (poly) & 141 & 15.1 & $13.9(11.6-16.5)$ \\
\hline Div/sep/wid ${ }^{b}$ & 228 & 24.4 & $24.1(20.7-27.4)$ \\
\hline \multicolumn{4}{|l|}{ Ever been married } \\
\hline Yes & 634 & 67.8 & $66.2(62.2-70.1)$ \\
\hline No & 301 & 32.2 & $33.8(30.0-37.8)$ \\
\hline
\end{tabular}

Pregnancies in life, number

$\begin{array}{lll}0 & 74 & 8.1 \\ 1 & 174 & 19.0 \\ 2 & 173 & 18.9 \\ 3 & 164 & 17.9 \\ 4 & 134 & 14.6 \\ 5+ & 196 & 21.4\end{array}$

Ever aborted a pregnancy

$\begin{array}{lll}\text { Yes } & 257 & 27.5 \\ \mathrm{No}^{\mathrm{c}} & 679 & 72.5\end{array}$

Use of modern family planning ${ }^{\mathrm{e}}$

$\begin{array}{lll}\text { Yes } & 624 & 67.0 \\ \text { No } & 307 & 33.0\end{array}$

Steady male sex partners last 30 days, number

$\begin{array}{llll}0 & 168 & 18.2 & 18.5(15.4-21.8) \\ 1 & 288 & 31.1 & 31.1(27.2-35.0) \\ 2 & 194 & 21.0 & 20.5(17.2-23.3) \\ 3+ & 275 & 29.7 & 29.9(26.5-34.0) \\ \text { Sex work main income } & & & \\ \text { Yes } & 808 & 88.4 & 87.1(84.5-89.8) \\ \text { No } & 106 & 11.6 & 12.9(10.2-15.4)\end{array}$

$14.6(11.8-17.1)$

$19.1(16.1-22.3)$

$24.9(21.5-28.6)$

$75.1(71.5-78.5)$
Table 2 Characteristics of female sex workers in Kampala, Uganda, 2008-09, N = 942 (Continued)

\begin{tabular}{lccc}
\hline Occupation other than sex work & & \\
No other work & 557 & 59.6 & $57.2(53.7-61.3)$ \\
Other & 113 & 12.1 & $13.5(10.8-16.3)$ \\
Self-employed & 148 & 15.8 & $16.3(13.5-19.1)$ \\
Restaurant/bar & 116 & 12.4 & $13.1(10.1-15.7)$ \\
\hline
\end{tabular}

${ }^{a}$ For each characteristic, the total sample size differs from 942 due to missing information

${ }^{\mathrm{b}}$ Divorced, separated, widowed

'Includes those who have never been pregnant

${ }^{d}$ For each characteristic, the total sample size differs from 942 due to missing information

eOral contraceptives, intra-uterine device, or injection (depot provera)

positive, $52 \%$ said that they were on anti-retroviral treatment (ART).

\section{HIV infection}

Of 942 participants, 323 tested HIV-positive, yielding a weighted HIV prevalence of $33.0 \%$ (95\% CI: $29.7 \%-$ 36.6\%). Table 3 shows the distribution of HIV infection by select characteristics. In this bivariate analysis, factors associated with HIV serostatus included age, marital status, number of pregnancies, self-reported HIV status, duration of selling sex, self-reported clinical signs and symptoms of STIs, and a history of previous HIV testing.

In the adjusted analysis (Table 4), factors independently associated with HIV positivity included increasing age, fewer years of schooling, having no other work than sex work, increasing numbers of pregnancies, never having had an abortion, never having had an HIV test, and a history of STI-related symptoms in the last 12 months. Further, testing positive for $N$. gonorrhea (vaginal or rectal), and testing positive for any STI was associated with being HIV-infected (Table 5).

\section{Discussion \\ Main finding}

We report here on the first RDS survey among FSW in Kampala, Uganda, using a sampling design that allows us to generate population estimates. The estimated HIV prevalence of $33 \%$ suggests an alarming HIV burden among FSW, more than three times that among Kampala women in general (9.5\% [9]). This estimate is similar to that reported as the baseline in a cohort study in Kampala conducted at approximately the same time [10]. Our population-based survey, using a probability sample, can serve as a baseline estimate for subsequent surveys in this population in Kampala. The median duration of sex work at time of survey participation was just 3 years. The much higher HIV prevalence in FSW compared to Kampala women in general together with the relatively short median duration of 
Table 3 Association between sociodemographic or behavioral characteristics of female sex workers and HIV infection in Kampala,

Uganda

Characteristic $^{\mathrm{d}}$

Age, years

15-19

20-24

25-29

$30+$

Nationality

Ugandan

Not Ugandan

Religion

Catholic

Protestant

Born Again

Moslim

Other

Schooling, years

$$
\begin{aligned}
& 0-3 \\
& 4-6
\end{aligned}
$$

$7+$

Sex work main income

Yes

No

Occupation other than sex work

No other work

Other

Self-employed

Restaurant/bar

Marital status

Never married

Cohabitating

Married (mono)

Married (poly)

Div/sep/wid

Pregnancies in life, number

$$
0
$$

1

2

3

$$
4
$$

$5+$

\section{Ever aborted}

$\begin{array}{ll}\text { Yes } & 231 \\ \mathrm{No}^{\mathrm{h}} & 702\end{array}$

Steady male sex partners last 30 days, number
HIV+

$$
11
$$

65

88

157

293

894

304

16

362

262

47

232

30

251

185

482

806

106

557

112

147

115

300

210

53

141

228

74

173

173

134

196

231

02

16

13

107

70

137

28

201

26

53

36

105
Weighted \%

$P$-value ${ }^{e}$

Prevalence Ratio (95\% Cl)

10.8

21.9

35.9

50.7

33.0

33.1

35.4

30.9

37.0

28.5

42.9

42.1

36.6

26.4

35.1

20.9

36.9

19.2

32.3

26.7

23.4

37.8

23.0

36.5

41.9

3.6

21.0

33.4

44.8

46.5

38.7

27.4

$260 \quad 34.7$

$<0.01$

1.00 (Referent)

$2.03(1.04-3.95)$

$3.33(1.74-6.40)$

$4.71(2.50-8.89)$

0.99

1.00 (Referent)

$1.00(0.61-1.65)$

0.41

1.00 (Referent)

$0.87(0.68-1.13)$

$1.05(0.64-1.71)$

$0.81(0.61-1.07)$

$1.21(0.74-1.98)$

$<0.01$

1.00 (Referent)

0.87 (0.66-1.14)

$0.63(0.49-0.80)$

$<0.01$

$1.68(1.13-2.51)$

1.00 (Referent)

$<0.01$

1.00 (Referent)

$0.52(0.34-0.79)$

$0.88(0.66-1.17)$

$0.72(0.50-1.05)$

$<0.01$

$1.02(0.57-1.83)$

$1.64(0.93-2.91)$

1.00 (Referent)

$1.59(0.88-2.86)$

$1.84(1.04-3.20)$

$<0.01$

1.00 (Referent)

$5.88(2.00-17.3)$

$9.34(3.26-26.8)$

$12.5(4.40-35.5)$

$13.0(4.56-36.9)$

$10.8(3.81-30.7)$
$0.79(0.60-1.03)$

0.07

1.00 (Referent) 
Table 3 Association between sociodemographic or behavioral characteristics of female sex workers and HIV infection in Kampala, Uganda (Continued)

\begin{tabular}{|c|c|c|c|c|c|}
\hline 0 & 167 & 68 & 40.4 & 0.18 & 1.00 (Referent) \\
\hline 1 & 288 & 105 & 33.3 & & $0.82(0.62-1.09)$ \\
\hline 2 & 192 & 57 & 28.0 & & $0.69(0.50-0.96)$ \\
\hline $3+$ & 275 & 86 & 31.7 & & $0.79(0.59-1.05)$ \\
\hline \multicolumn{6}{|c|}{ Alcohol before last sex } \\
\hline Yes & 480 & 173 & 35.0 & 0.25 & $1.13(0.92-1.40)$ \\
\hline No & 455 & 147 & 31.0 & & 1.00 (Referent) \\
\hline \multicolumn{6}{|c|}{ Drugs for pleasure } \\
\hline Yes & 217 & 71 & 34.0 & 0.71 & $1.05(0.82-1.34)$ \\
\hline No & 708 & 244 & 32.4 & & 1.00 (Referent) \\
\hline \multicolumn{6}{|c|}{ Inject drugs } \\
\hline Yes & 42 & 16 & 40.6 & 0.38 & $1.24(0.80-1.91)$ \\
\hline $\mathrm{No}^{\mathrm{i}}$ & 886 & 303 & 32.8 & & 1.00 (Referent) \\
\hline \multicolumn{6}{|c|}{ Years selling sex, number } \\
\hline$<1$ & 13 & 4 & 32.7 & 0.02 & 1.00 (Referent) \\
\hline 1 & 148 & 34 & 21.3 & & $0.65(0.26-1.62)$ \\
\hline 2 & 179 & 58 & 31.4 & & $0.96(0.40-2.31)$ \\
\hline 3 & 177 & 62 & 32.3 & & $0.99(0.41-2.36)$ \\
\hline 4 & 74 & 23 & 33.6 & & $1.03(0.41-2.57)$ \\
\hline $5+$ & 335 & 136 & 39.9 & & $1.22(0.52-2.87)$ \\
\hline \multicolumn{6}{|c|}{ Condom use during last sex with a male client } \\
\hline Yes & 619 & 208 & 32.0 & 0.50 & $0.93(0.75-1.15)$ \\
\hline No & 315 & 111 & 34.6 & & 1.00 (Referent) \\
\hline \multicolumn{6}{|c|}{ Ever used condom } \\
\hline Yes & 872 & 301 & 33.3 & 0.54 & 1.00 (Referent) \\
\hline No & 56 & 16 & 28.9 & & $0.87(0.53-1.41)$ \\
\hline \multicolumn{6}{|c|}{ Ever used lubricant } \\
\hline Yes & 282 & 90 & 30.8 & 0.44 & 1.00 (Referent) \\
\hline No & 648 & 228 & 33.6 & & $1.09(0.87-1.38)$ \\
\hline \multicolumn{6}{|c|}{ Violence due to selling sex } \\
\hline Yes & 433 & 163 & 35.9 & 0.13 & $1.17(0.95-1.45)$ \\
\hline No & 498 & 155 & 30.5 & & 1.00 (Referent) \\
\hline \multicolumn{6}{|c|}{ Raped in last 30 days, number } \\
\hline $0^{c}$ & 619 & 206 & 32.4 & 0.38 & 1.00 (Referent) \\
\hline 1 & 93 & 36 & 36.2 & & $1.12(0.77-1.62)$ \\
\hline 2 & 81 & 25 & 27.3 & & $0.84(0.57-1.26)$ \\
\hline 3 & 43 & 20 & 47.9 & & $1.48(1.02-2.15)$ \\
\hline $4+$ & 91 & 28 & 31.6 & & $0.97(0.68-1.40)$ \\
\hline \multicolumn{6}{|c|}{ Raped by customer in last 30 days, number } \\
\hline $0^{j}$ & 682 & 228 & 32.4 & 0.94 & 1.00 (Referent) \\
\hline 1 & 124 & 40 & 30.0 & & $0.92(0.65-1.32)$ \\
\hline 2 & 71 & 26 & 36.1 & & $1.11(0.77-1.60)$ \\
\hline 3 & 25 & 9 & 31.9 & & $0.98(0.51-1.91)$ \\
\hline $4+$ & 23 & 8 & 38.4 & & $1.18(0.64-2.20)$ \\
\hline
\end{tabular}


Table 3 Association between sociodemographic or behavioral characteristics of female sex workers and HIV infection in Kampala, Uganda (Continued)

Sex partners, total number in last 30 days

$\begin{array}{llll}0-12 & 221 & 71 & 29.9 \\ 13-24 & 234 & 75 & 31.8 \\ 25-58 & 248 & 87 & 36.2 \\ 59+ & 236 & 88 & 34 .\end{array}$

$$
0.59
$$

Male partners in life, number

$\begin{array}{ll}1-24 & 201 \\ 25-64 & 2 \\ 65-194 & 2 \\ 195+ & 209\end{array}$

Vaginal discharge/burning in last 12 months

Yes

No

\section{4}

280

Genital ulcer/sore in last 12 months

$\begin{array}{ll}\text { Yes } & 520 \\ \text { No } & 409\end{array}$

Anal ulcer/sore in last 12 months

$$
\text { Yes }
$$

No

520
409

$$
58
$$

$$
76
$$$$
73
$$

25.1

34.6

33.1

09

0.08

$<0.01$

0.03

Anal discharge in last 12 months

$\begin{array}{ll}\text { Yes } & 124 \\ \text { No } & 791\end{array}$

$\begin{array}{lll}124 & 42 & 33.8 \\ 791 & 270 & 32.4\end{array}$

Anal warts in last 12 months

Yes

Ever had anal sex

$\begin{array}{ll}\text { Yes } & 171 \\ \text { No } & 758\end{array}$

$171 \quad 62$

Ever had HIV test

$\begin{array}{ll}\text { Yes } & 503 \\ \text { No } & 430\end{array}$

Had steady male sex partners last 30 days

$$
\text { Yes }
$$

1.00 (Referent)

$1.06(0.78-1.45)$

$1.21(0.90-1.62)$

$1.15(0.85-1.55)$

1.00 (Referent)

1.38 (0.98-1.93)

$1.32(0.94-1.86)$

$1.53(1.09-2.13)$

$1.31(1.02-1.68)$

1.00 (Referent)

1.58 (1.26-1.98)

1.00 (Referent)

1.32 (1.05-1.65)

1.00 (Referent)

$1.04(0.77-1.41)$

1.00 (Referent)

$<0.01$

1.65 (1.32-2.08)

1.00 (Referent)

${ }^{\mathrm{d}}$ For each characteristic, the total sample size differs from 942 due to missing information

${ }^{\mathrm{e}} \mathrm{Chi}$-squared test of independence between the characteristic and HIV positivity

${ }^{f}$ For each characteristic, the total sample size differs from 942 due to missing information

${ }^{9}$ Chi-squared test of independence between the characteristic and HIV positivity

hincludes those who have never been pregnant

IInlcudes those who have never used drugs

Includes those who have never been raped

sex work would suggest a very high HIV incidence, although our cross-sectional survey design did not allow us to estimate HIV incidence. In adjusted analysis, increasing age, low levels of schooling, having no other work, lack of ever having tested for HIV, self-reported genital ulcers or sores, as well as testing positive for $N$. gonorrhea or any STI were associated with being HIVinfected.

\section{Limitations and strengths}

Our survey's limitations mostly relate to the RDS design, which may not have been able to reach isolated 
Table 4 Factors associated with HIV infection among female sex workers, Kampala, Uganda, 2008-09

\begin{tabular}{lllll}
\hline Characteristic & $\mathrm{n}$ & $\mathrm{HIV}+$ & Weighted \% & Adjusted PR $(95 \% \mathrm{Cl})^{\mathrm{a}}$ \\
\hline Age, years & & & & \\
$15-19$ & 109 & 11 & 10.8 & 1.00 (Referent) \\
$20-24$ & 291 & 65 & 21.9 & $1.27(0.74-2.19)$ \\
$25-29$ & 246 & 88 & 35.9 & $1.64(0.92-2.90)$ \\
$30+$ & 293 & 157 & 50.7 & $2.13(1.19-3.80)$ \\
Schooling, years & & & & \\
$1-3$ & 251 & 107 & 42.1 & 1.00 (Referent) \\
$4-6$ & 185 & 70 & 36.6 & 0.82 (0.63-1.07) \\
$7+$ & 482 & 137 & 26.4 & $0.67(0.54-0.84)$
\end{tabular}

Occupation other than sex work

$\begin{array}{lllll}\text { No other work } & 557 & 201 & 36.9 & 1.00 \text { (Referent) } \\ \text { Other } & 112 & 26 & 19.2 & 0.55(0.37-0.81) \\ \text { Self-employed } & 147 & 53 & 32.3 & 0.74(0.55-0.99) \\ \text { Restaurant/bar } & 115 & 36 & 26.7 & 0.80(0.60-1.08)\end{array}$

Pregnancies in life, number

$\begin{array}{lllll}0 & 74 & 4 & 3.6 & 1.00 \text { (Referent) } \\ 1 & 173 & 36 & 21.0 & 7.24(2.14-24.5) \\ 2 & 173 & 61 & 33.4 & 9.43(2.75-32.3) \\ 3 & 162 & 65 & 44.8 & 11.7(3.38-40.7) \\ 4 & 134 & 60 & 46.5 & 10.8(3.06-37.9) \\ 5+ & 196 & 86 & 38.7 & 8.23(2.29-29.6)\end{array}$

Ever aborted

$\begin{array}{lllll}\text { Yes } & 231 & 60 & 27.4 & 0.76(0.59-0.97) \\ \text { No } & 702 & 260 & 34.7 & 1.00 \text { (Referent) }\end{array}$

Genital ulcer/sore in last 12 months

$\begin{array}{lllll}\text { Yes } & 520 & 211 & 39.6 & 1.39(1.13-1.71) \\ \text { No } & 409 & 107 & 25.0 & 1.00 \text { (Referent) }\end{array}$

Anal warts in last 12 months

$\begin{array}{lllll}\text { Yes } & 132 & 65 & 49.7 & 1.43(1.14-1.80) \\ \text { No } & 783 & 247 & 30.0 & 1.00 \text { (Referent) }\end{array}$

Ever had HIV test

$\begin{array}{lllll}\text { Yes } & 503 & 120 & 23.0 & 1.00 \text { (Referent) } \\ \text { No } & 430 & 199 & 44.6 & 1.71(1.39-2.10)\end{array}$

NOTE: PR, prevalence ratio

${ }^{a}$ The multivariable model included all of the factors in this table. The sample size for the model was 861 female sex workers

sex workers with few or no peer connections. Also, as in all surveys, all behavioral parameters evaluated here are based on self-reported interview data, which are subject to reporting bias. The use of ACASI in our survey likely can be seen as a strength, as it facilitates the reporting of sensitive behaviors [20-22], augmented by the objective biomarker collection using blood as well as vaginal and rectal swabs. The survey's main strength
Table 5 Association between other sexually transmitted infections and HIV infection among female sex workers, Kampala, Uganda, 2008-09

\begin{tabular}{lllll}
\hline $\mathrm{STI}^{\mathrm{a}}$ & $\mathrm{n}$ & $\mathrm{HIV}+$ Weighted \% & $\begin{array}{l}\text { Adjusted PR } \\
(95 \% \mathrm{Cl})^{\mathrm{b}}\end{array}$ \\
\hline $\begin{array}{l}\text { Syphilis } \\
\text { Positive }\end{array}$ & 193 & 81 & 38.9 & 1.22 (0.98-1.52) \\
Negative & 745 & 239 & 31.2 & 1.00 (Referent)
\end{tabular}

Chlamydia trachomatis vaginal

$\begin{array}{lllll}\text { Positive } & 39 & 8 & 16.9 & 0.90(0.54-1.51) \\ \text { Negative } & 683 & 239 & 33.9 & 1.00 \text { (Referent) }\end{array}$

Chlamydia trachomatis rectal

$\begin{array}{lllll}\text { Positive } & 22 & 4 & 13.2 & 0.80(0.30-2.10) \\ \text { Negative } & 706 & 246 & 33.8 & 1.00 \text { (Referent) }\end{array}$

Neisseria gonorrhoeae

vaginal

$\begin{array}{lllll}\text { Positive } & 55 & 29 & 49.2 & 1.64(1.27-2.10) \\ \text { Negative } & 667 & 218 & 31.8 & 1.00 \text { (Referent) }\end{array}$

Neisseria gonorrhoeae rectal

$\begin{array}{lllll}\text { Positive } & 27 & 16 & 58.9 & 1.96(1.44-2.66) \\ \text { Negative } & 701 & 234 & 32.4 & 1.00 \text { (Referent) }\end{array}$

Trichomonas vaginalis

$\begin{array}{lllll}\text { Positive } & 73 & 26 & 32.5 & 1.00 \text { (0.70-1.42) } \\ \text { Negative } & 773 & 263 & 33.3 & 1.00 \text { (Referent) } \\ \begin{array}{l}\text { Bacterial vaginosis } \\ \text { Positive }\end{array} & & & & \\ \text { Negative } & 318 & 128 & 39.9 & 1.19 \text { (0.98-1.46) } \\ \text { S26 } & 160 & 29.0 & 1.00 \text { (Referent) }\end{array}$

Any STI

$\begin{array}{lllll}\text { Positive } & 511 & 197 & 37.2 & 1.28 \text { (1.05-1.56) } \\ \text { Negative } & 431 & 126 & 27.9 & 1.00 \text { (Referent) }\end{array}$

NOTE: STI, sexually transmitted infection; PR, prevalence ratio ${ }^{\mathrm{a}}$ For each STI, the total sample size differs from 942 due to missing information

${ }^{\mathrm{b}}$ Adjusted for age, schooling, occupation other than sex work, number of pregnancies in life, ever aborted, genital ulcer/sore in last 12 months, anal warts in last 12 months, and ever had an HIV test

likely lies in its sampling design using RDS. Previous FSW surveys used convenience sampling [10], making this the first representative sex worker survey in Kampala.

\section{Implications for policy and program}

Our survey's findings call for targeted strengthening of programs promoting condom use (among both sex workers and clients), regular HIV and STI testing, preexposure prophylaxis, and prompt treatment among FSW. Although almost all FSW reported some condom use, about one third did not use condoms at their last commercial sex act, an estimate that may further suffer from reporting bias despite the ACASI-based interview 
format. Consistent and correct condom use is highly effective against HIV and STI transmission and needs to be a cornerstone in sex work-based HIV control efforts. [5] Only one in seven Kampala FSW had tested for HIV in the preceding 12 months. UN and donor agencies recommend universal access to comprehensive HIV services for sex workers as a central component of policies related to sex work. [5] Regular HIV testing, at least annually, is warranted for a population at such high risk for HIV infection. [5] Our observation of self-reported anal sex by approximately one in five sex workers suggests that prevention and counseling services in Uganda need to address this high-risk behavior. Barriers to HIV testing, counseling, and related health care for sex workers, described both in Uganda and elsewhere in Africa and fueled by criminalization and stigma [23], need to be overcome.

Screening for STI is not widely available for sex workers in Uganda, is often based on syndromic management and rarely includes management of rectal STI. Our survey confirms the presence of common STI among FSW based on both self-report of genital and anal ulcers and biological testing for trichomoniasis, syphilis, chlamydia, and gonorrhea. In addition to the disease burden they inflict by themselves, STI increase the risk of HIV transmission. [24, 25] Regular screening for STI or - in its absence - presumptive treatment as recommended by UNAIDS [5] should therefore be considered through public or non-profit programs tailored for FSW in order to minimize exposure to stigma, along with increased investment in laboratory testing capacity for common STI.

Added to the low rate of HIV testing is the equally low reported rate of disclosing their HIV test result to their sex partners and the uptake of ART among HIVpositive FSW. Recent guidance by the World Health Organization [26] suggests that all FSW, and indeed all key populations, should take antiretrovirals either for treatment (HIV-infected, regardless of CD4+ T-cell count) or for pre-exposure prophylaxis (HIV-uninfected). This implies not only frequent HIV testing and self-disclosure by sex workers but also increased efforts by health care providers to facilitate access, reduce stigma, and counsel for HIV status disclosure to their partners.

Of grave concern is the frequent experience of genderbased violence (GBV) among FSW, including rape and beatings. UNAIDS' vision of zero new HIV infections, zero discrimination, and zero AIDS-related deaths also includes zero tolerance for GBV [27]. GBV against FSW are well documented in Uganda [28] and elsewhere in the region. $[15,29]$ Decriminalization of sex work as well as programs to eliminate and to provide redress for violence and discrimination should be put in place.
The high burden of HIV disease among sex workers in Kampala suggests that the goal of 90\%-90\%-90\% targets for testing, treatment and viral load suppression and the vision of an AIDS-free generation will not be achieved unless the HIV epidemic in this key population is contained. In addition to the use of antiretrovirals, recommendations for controlling sex work-related HIV transmission include decriminalization of sex work, which may also reduce stigma and violence; improved access to HIV testing, STI screening, and other prevention and treatment services; as well as peer education and peer-led interventions such as condom negotiation skills and other health promotion measures $[5,30]$. To achieve this, community-based sex worker organizations in Uganda need to be seen as essential partners in combating sex work-related HIV and STIs.

The effectiveness of HIV control and other public health measures in hidden populations such as sex workers requires regular monitoring of endpoints such as the incidence or prevalence of HIV, estimates of viral load suppression, and perhaps testing for antiretrovirals. In order to evaluate and inform control programs, population-based surveys using rigorous sampling designs need to be conducted regularly given the likely high HIV incidence, geographic and occupational mobility, and levels of access to and uptake of HIV services that may not mirror that in the general population.

\section{Conclusions}

FSW in Kampala are at an extremely high risk for HIV infection and violence. To achieve the laudable and ambitious goal of zero new infections, key populations such as sex workers need to be included in all aspects of HIV prevention, care, and treatment programs. Uganda's national AIDS control strategy needs to recognize the HIV epidemic in sex workers as a public health crisis that will not cede without intensified public health efforts.

\section{Endnotes}

${ }^{1}$ By $2020,90 \%$ of all people living with HIV will know their HIV status; $90 \%$ of all people with diagnosedHIV infection will receive sustained antiretroviral therapy; and $90 \%$ of all people receiving antiretroviral therapy will have viral suppression.

\footnotetext{
Abbreviations

ACASI: Audio computer assisted self interview; AIDS: Acquired immunodeficiency syndrome; ART: Antiretroviral therapy; CD: Compact disc; CDC: Centers for Disease Control and Prevention; Cl: Confidence intervals; CT: Chlamydia trachomatis; FSW: Female sex worker(s); GBV: Gender-based violence; HIV: Human immunodeficiency virus; IQR: Interquartile range; MP3: MPEG-1 and/or MPEG-2 Audio Layer III; NG: Neisseria gonorrhea; RDS : Respondent driven sampling; SAS: Statistical Analysis System; STD: Sexually transmitted diseases; STI: Sexually transmitted infections; TP: Treponema pallidum; UK: United Kingdom; UN: United Nations; UNAIDS: Joint United Nations Programme on AIDS; USA: United States of America
} 


\section{Acknowledgement}

The authors thank the Crane Survey staff and survey respondents for their work and participation in this survey. The Crane Survey group includes Herbert Kiyingi, Enos Sande, Geoffrey Musinguzi, David Serwadda, Wolfgang Hladik, Alex Opio, and Michael Muyonga.

\section{Funding}

This project has been supported by the President's Emergency Plan for AIDS Relief (PEPFAR) through the Centers for Disease Control and Prevention under the terms of cooperative agreement 5U2GPS000971.

\section{Availability of data and materials}

Data are available upon request to the first author for third party researchers meeting the criteria for access to confidential data.

\section{Authors' contributions}

$\mathrm{WH}, \mathrm{JB}$, and $\mathrm{AB}$ wrote the manuscript. $\mathrm{AB}$ performed the data analysis. All authors read, reviewed, commented and approved the final manuscript.

\section{Competing interests}

The authors declare that they have no competing interests.

\section{Consent for publication}

Not applicable.

\section{Ethics approval and consent to participate}

Both the main survey protocol and the formative research protocol were approved by the Uganda Virus Research Institute's institutional review board, the Uganda National Council of Science and Technology, and was determined as a non-research/surveillance activity by the CDC. In order to protect anonymity, participants provided verbal informed consent which was documented by survey staff. No parental consent was sought. The IRB approved protocol allowed us to consent the candidate participants without parental consent because sex workers were deemed emancipated minors who cater for their own livelihoods, as per Uganda National Council of Science and Technology guidelines.

\section{Disclaimer}

The findings and conclusions in this report are those of the authors and do not necessarily represent the official position of the U.S. Department of Health and Human Services.

\section{Publisher's Note}

Springer Nature remains neutral with regard to jurisdictional claims in published maps and institutional affiliations.

\section{Author details}

'Division of Global HIV and TB, Center for Global Health, Centers for Disease Control and Prevention, 1600 Clifton Rd, Atlanta, GA 30333, USA. ${ }^{2}$ Makerere University College of Health Sciences, School of Public Health, Kampala, Uganda. ${ }^{3}$ Division of Global Health Protection, Center for Global Health, Centers for Disease Control and Prevention, Atlanta, GA, USA. ${ }^{4}$ WONETHA Women's Organisation Network for Human Rights Advocacy, Kampala, Uganda.

Received: 31 August 2016 Accepted: 15 May 2017

\section{Published online: 10 June 2017}

\section{References}

1. AIDS by the numbers 2015. Geneva, 2015; UNAIDS. http://www.unaids.org/ sites/default/files/media_asset/AIDS_by_the_numbers_2015_en.pdf. Accessed 20 Dec 2015.

2. Understanding Fast-Track. Accelerating Action to End the AIDS Epidemic by 2030. UNAIDS. Geneva, 2015. at http:/www.unaids.org/sites/default/files/media_ asset/201506_JC2743_Understanding_FastTrack_en.pdf. Accessed 20 Dec 2015.

3. Baral S, Beyrer C, Muessig K, Poteat T, Wirtz AL, Decker MR, et al. Burden of HIV among female sex workers in low-income and middle-income countries: a systematic review and meta-analysis. Lancet Infect Dis. 2012;12(7):538-49.

4. Global report: UNAIDS report on the global AIDS epidemic 2012. Joint United Nations Programme on HIV/AIDS (UNAIDS). Geneva, 2012. at http:// files.unaids.org/en/media/unaids/contentassets/documents/epidemiology/ 2012/gr2012/20121120_UNAIDS_Global_Report_2012_with_annexes_en.pdf. Accessed 17 Mar 2013

5. Prevention and Treatment of HIV and other Sexually Transmitted Infections for Sex Workers in Low- and Middle-income Countries. Recommendations for a public health approach. World Health Organization. Geneva. 2012 at http://apps.who.int/iris/bitstream/10665/77745/1/9789241504744_eng.pdf. Accessed 12 July 2015

6. The Global HIV Epidemics among Sex Workers. World Bank. Washington. doi: 10.1596/978-0-8213-9774-9. at https://issuu.com/world.bank. publications/docs/9780821397749. Accessed 12 July 2015.

7. Shannon K, Strathdee SA, Goldenberg SM, Duff P, Mwangi P, Rusakova M, et al. Global epidemiology of HIV among female sex workers: influence of structural determinants. Lancet. 2015;385(9962):55-71.

8. Pruss-Ustun A, Wolf J, Driscoll T, Degenhardt L, Neira M, Calleja JM. HIV due to female sex work: regional and global estimates. PLoS One. 2013:8(5):e63476.

9. Ministry of Health (MOH) [Uganda] and ICF International. Uganda AIDS Indicator Survey 2011. Kampala, Uganda and Calverton, Maryland; ICF International; 2012.

10. Vandepitte J, Bukenya J, Weiss HA, Nakubulwa S, Francis SC, Hughes P, et al. HIV and other sexually transmitted infections in a cohort of women involved in high-risk sexual behavior in Kampala, Uganda. Sex Transm Dis. 2011;38(4):316-23.

11. Uganda HIV Modes of Transmission and Prevention Response Analysis. Uganda AIDS Commission and UNAIDS. 2009, Kampala, Uganda. at http:// www.k4health.org/sites/default/files/ HIV\%20Modes\%20of\%20Transmission\%20and\%20Response\%20Analysis\% 20Ug\%202009.pdf. Accessed 18 Mar 2013.

12. Heckathorn DD. Respondent-driven sampling: a new approach to the study of hidden populations. Soc Probl. 1997:44(2):174-99.

13. Heckathorn DD. Extensions of respondent-driven sampling: analyzing continuous variables and controlling for differential recruitment. Soc Method. 2004;34(151):208.

14. Heckathorn DD. Respondent-driven sampling II: deriving valid population estimates from chain-referral samples of hidden populations. Soc Probl. 2007:49(1):11-34.

15. Ombeni AM, Crago AL. Violence against sex workers by police and military in Democratic Republic of Congo. HIV/AIDS policy \& law review / Canadian HIV/AIDS Legal Network. 2008;13(2-3):73-4.

16. Salganik MJ. Variance estimation, design effects, and sample size calculations for respondent-driven sampling. J Urban Health. 2006;83(6 Suppl):i98-112.

17. Research Triangle Institute. SUDAAN language manual, volumes 1 and 2 , release 11. Research Triangle Park: Research Triangle Institute; 2012.

18. Bieler GS, Brown GG, Williams RL, Brogan DJ. Estimating model-adjusted risks, risk differences, and risk ratios from complex survey data. Am J Epidemiol. 2010;171(5):618-23.

19. Victora CG, Huttly SR, Fuchs SC, Olinto MT. The role of conceptual frameworks in epidemiological analysis: a hierarchical approach. Int J Epidemiol. 1997;26(1):224-7.

20. Ghanem KG, Hutton HE, Zenilman JM, Zimba R, Erbelding EJ. Audio computer assisted self interview and face to face interview modes in assessing response bias among STD clinic patients. Sex Transm Infect. 2005;81(5):421-5.

21. Perlis TE, Des Jarlais DC, Friedman SR, Arasteh K, Turner CF. Audio-computerized self-interviewing versus face-to-face interviewing for research data collection at drug abuse treatment programs. Addiction. 2004;99(7):885-96.

22. Tideman RL, Chen MY, Pitts MK, Ginige S, Slaney M, Fairley CK. A randomised controlled trial comparing computer-assisted with face-to-face sexual history taking in a clinical setting. Sex Transm Infect. 2007;83(1):52-6.

23. Scorgie F, Nakato D, Harper E, Richter M, Maseko S, Nare P, et al. 'We are despised in the hospitals': sex workers' experiences of accessing health care in four African countries. Culture, health \& sexuality. 2013;15(4):450-65.

24. Fleming DT, Wasserheit JN. From epidemiological synergy to public health policy and practice: the contribution of other sexually transmitted diseases to sexual transmission of HIV infection. Sex Transm Infect. 1999;75(1):3-17.

25. Galvin SR, Cohen MS. The role of sexually transmitted diseases in HIV transmission. Nat Rev Microbiol. 2004;2(1):33-42.

26. Guideline on when to start antiretroviral therapy and on pre-exposure prophylaxis for HIV. World Health Organization, Geneva, 2015. at http://apps. 
who.int/iris/bitstream/10665/186275/1/9789241509565_eng.pdf?ua=1. Accessed 27 Dec 2015

27. Getting to zero: 2011-2015 strategy. Joint United Nations Programme on HIV/AIDS (UNAIDS). Geneva 2012. at http://files.unaids.org/en/media/unaids/ contentassets/documents/unaidspublication/2010/JC2034_UNAIDS_ Strategy_en.pdf. Accessed 17 Mar 2013.

28. Mbonye M, Nalukenge W, Nakamanya S, Nalusiba B, King R, Vandepitte J, et al. Gender inequity in the lives of women involved in sex work in Kampala, Uganda. J Int AIDS Soc. 2012;15(Suppl 1):1-9.

29. Okal J, Chersich MF, Tsui S, Sutherland E, Temmerman M, Luchters S. Sexual and physical violence against female sex workers in Kenya: a qualitative enquiry. AIDS Care. 2011;23(5):612-8.

30. World Health Organization. Preventing HIV in sex work settings in sub-Saharan Africa. Geneva: World Health Organization. 2011. http://apps.who.int/iris/ bitstream/10665/44549/1/9789241501279_eng.pdf. Accessed 27 May 2017.

Submit your next manuscript to BioMed Central and we will help you at every step:

- We accept pre-submission inquiries

- Our selector tool helps you to find the most relevant journal

- We provide round the clock customer support

- Convenient online submission

- Thorough peer review

- Inclusion in PubMed and all major indexing services

- Maximum visibility for your research

Submit your manuscript at www.biomedcentral.com/submit
Biomed Central 